\title{
Correspondence between the objective and subjective economies: the role of personal economic circumstances
}

\author{
Marta Fraile (IPP, CSIC) \& Sergi Pardós-Prado (University of Oxford) \\ Published at Political Studies 62(4): 895-912 (doi: 10.1111/1467-9248.12055)
}

ABSTRACT: The impact of sociotropic economic satisfaction on the vote has been thoroughly analyzed. However, knowledge about how citizens acquire information about the economy and the degree of correspondence between objective macro-economic changes and citizens' subjective economic perceptions is much more limited. While the effect of partisan rationalization has recently received some attention, the role of objective personal economic conditions in assessing national economic conditions is still unclear. We suggest that macro-economic changes have some impact on subjective economic satisfaction, especially among higher income and socio-professional strata with higher risk aversion rates to negative macro-economic shocks. The results are obtained via 3level hierarchical linear models using the cumulative file of the European Social Survey (2002-2009) and confirm the relevance of citizens' personal economic circumstances as a filter to perceive the state of the economy.

Keywords: economic perceptions, sociotropic perceptions, macro-economic changes, personal economic conditions

\section{Introduction}

A considerable amount of research has analyzed the impact of individual economic perceptions of the national economy on vote choice. The causal connection between economic perceptions and vote choice is based on two main nexuses (Lewis-Beck and Paldam, 2000). The first goes from objective macro-economic results to voters' perceptions, and the second from voters' perceptions to their voting decisions. While the latter nexus has received a lot of attention, the former has been much less studied. Apart from some contested evidence about the correspondence between the objective and the 
subjective economy, the different mechanisms through which citizens acquire information about the economy still remain unclear (Anderson, 2007; Duch and Stevenson, 2010a; Duch and Stevenson, 2010b; Evans and Pickup, 2010). Studying the connection between objective macro-economic conditions and subjective perceptions is pivotal, given the critical importance of this link for the accountability of democratic representation (Evans and Pickup, 2010; Nadeau, Lewis-Beck and Belanger, forthcoming). If the electorate incorrectly interprets the economic situation in a given country, punishing or rewarding governments for their management of the economy will be far from the ideal of a fair and functional mechanism of representation.

In this article, and in line with the few previous contributions on the topic, we suggest that macro-economic changes have an impact on individual satisfaction with the state of the economy. However, we argue that this connection is conditioned by objective personal economic situations. Relying on axioms derived from an asset theory of social policy preferences (Iversen and Soskice, 2001), we hypothesize that citizens with higher income and higher socio-professional status will be more sensitive to objective macroeconomic changes. According to this theory, it can be expected that people in the higher strata are more risk averse because of the greater potential marginal cost they may experience if the economy performs poorly. This is so because people in the higher strata have more to lose, because they have presumably assumed more investment costs, and because these factors make them more receptive to the objective macro-economic situation. This expectation implies that citizens in the higher income and status strata will be comparatively more satisfied than citizens in the lower strata when the economy improves; and more dissatisfied when the economy worsens. In contrast, since people in the lower 
strata were already in a difficult situation before a given macro-economic shock, their level of economic satisfaction should be less dependent on the objective economy. These expectations are tested with cross-national and cross-time data drawn from the European Social Survey cumulative file. The results are in line with expectations, thereby suggesting that the degree of correspondence between the economic reality and citizens' economic perceptions is greater the higher their level of income and status.

The contribution of this article to the discussion of the sources of citizens' economic perceptions is two-fold. First, we attempt to deepen the understanding of the link between the objective economy and subjective economic perceptions (Lewis-Beck and Stegmaier, 2000; Anderson, 2007). Some researchers have considered objective economic indicators (Van der Eijk et al., 2007) and subjective ones (Duch and Stevenson, 2008; Nadeau, LewisBeck and Belanger, forthcoming) in either/or terms, without dealing with their potential interrelation (Evans and Pickup, 2010, p. 1237). If such an interrelation exists, then assuming an independent and additive effect of subjective and objective dimensions of the economy can lead to biased results. Secondly, we focus on an as yet unexplored source of individual-level heterogeneity, namely objective personal economic conditions. While the recent debate on economic perceptions seems to predominantly focus on the effect of partisan biases (Duch and Stevenson, 2010b; Evans and Andersen, 2006; Lewis-Beck, Nadeau and Elias, 2008; Evans and Pickup, 2010; Nadeau, Lewis-Beck and Belanger, forthcoming) and cognitive engagement (Duch, Palmer and Anderson, 2000), the conditional effect of objective personal economic situations has received less attention. 


\section{Citizens' perceptions about the economy: personal economic circumstances as a filter}

The systematic analysis of the whole range of factors that can mediate the connection between objective macro-economic performance and individual subjective perceptions is still underdeveloped (Duch and Stevenson, 2008; Lewis-Beck and Stegmaier 2007; LewisBeck and Paldam, 2000; Van der Eijk et al., 2007; Anderson, 2007). In one of the few works that directly tackles the individual heterogeneity of economic perceptions, Duch, Palmer and Anderson (2000, p. 637-639) highlight four factors mediating the link between the objective and the subjective economy: information and media exposure, political attitudes, personal financial experience, and group self-interest.

First, information and media exposure refers to the effect that education, political sophistication and media exposure can exert in perceiving the economy. The main hypothesis states that the degree of accurateness of citizens' economic perceptions might increase with their access and incentive to obtain information about the economy (Popkin 1991; Duch and Stevenson 2008 and 2010b). Second, political attitudes refer to the effect that ideology and partisanship have on economic evaluations. This is consistent with the theory of limited rationality (Popkin, 1991; Sniderman, Brody and Tetlock, 1991), which argues that citizens can overcome the costs of acquiring complete information and knowledge about issues by using cognitive cues. According to this perspective, it is not necessary for a citizen to engage in a detailed analysis of the official statistics in order to have a general idea of the country's economic performance. The main expectation is that individuals with strong attachments to the incumbent may perceive the national economy more positively. This second source of subjective heterogeneity in evaluations of the 
national economy has recently generated an intense debate about the degree of exogeneity of these evaluations (Evans and Andersen 2006; Lewis-Beck, Nadeau and Elias 2008; Evans and Pickup 2010; Nadeau, Lewis-Beck and Belanger, forthcoming).

Third, personal financial experience refers to the potential effects of subjective evaluation of the personal economic situation (that is, egocentric economic views) on assessments about the state of the country's economy. Citizens experiencing personal (or family) financial troubles are expected to be more negative in their assessments about the economy. Finally, group self-interest refers to the potential influence of citizens' employment status or type of occupation sector on their views about the state of the national economy. Among all these factors, objective personal economic conditions in terms of income and socio-professional status (which would broadly fit into the self-interest category defined by Duch, Palmer and Anderson, 2000) are far less studied, and usually even forgotten, sources of individual heterogeneity (Anderson, 2007, pp. 278-281).

There are arguments supporting the idea that the macroeconomic knowledge of citizens will be scant because of the difficulties of obtaining information about the inflation rate, unemployment, or economic growth in a given country (Conover, Feldman and Knight, 1986). Hence, citizens will be more responsive to macroeconomic aggregates only when economic issues directly and personally affect their own interest or day-to-day life. From here it follows that beyond the direct relationship between objective economic conditions and subjective economic satisfaction, the latter can be much better explained through the influence of the personal economic situation of each citizen. One might expect, therefore, that individuals who are in economic difficulties will perceive the overall economic state of affairs differently from people who are in a more comfortable situation. 
From this perspective, personal economic circumstances can be considered as a filter that increases or decreases the saliency of a given objective macro-economic scenario.

It has been shown that being unemployed or working in the private sector, increase concern about the state of the economy (Singer, 2011). What remains to be seen, is whether objective personal economic conditions moderate the impact of macro-economic changes on the subjective economic views of citizens. Moreover, we explicitly model the interaction between macro-objective indicators and micro-objective variables in explaining subjective perceptions. In which way, then, could objective personal economic circumstances moderate the impact of macro-economic conditions on individual subjective views about the national economy? According to a recent theory of social policy preferences, individuals who have made risky investments and who therefore have higher potential marginal costs in case of an external economic shock will demand more insurance against the possible loss of income from those investments (Iversen and Soskice, 2001). Even if the outcome of interest in this theory is individual support for social spending and redistribution, the theoretical mechanisms behind the higher risk aversion of highly skilled citizens is directly applicable to our argument.

According to a classic political economic model developed by Meltzer and Richard (1981), workers with higher income are likely to demand less social protection than workers with lower income. The rationale behind this expectation is that higher income reduces the perceived risk of an eventual economic shock. This logic applied to the study of individual satisfaction towards the national economy would imply that people in the higher income strata are less sensitive to objective macro-economic changes, because they have greater economic resources. As pointed out by Iversen and Soskice (2001), however, 
the Meltzer-Richard argument ignores the insurance against investment risks aspect. Highly skilled and specialized workers in the high income strata will have more to lose in the case of an external economic shock, and will have more difficulties in finding a job requiring the same level of skills and providing the same level of economic reward. When a worsening external economic condition takes place, "an entirely new motive enters into workers' calculations of their interests: insurance against loss of income" (Iversen and Soskice, 2001:879). If workers are sufficiently risk-averse, then "rising income may be associated with increased demand for protection, since high-income workers have more to lose than low-income workers" (Iversen and Soskice, 2001:880).

The expectation that lower socioeconomic strata are more sensitive to certain macro-economic changes has influenced past research. Singer (forthcoming) finds that workers in developing countries who feel anxious about being fired or who perceive difficulties in finding a new job place greater weight on sociotropic evaluations than do those with more secure employment situations. According to the risk aversion argument suggested above and applied to developed countries, however, a segment of these workers may be high income and specialized individuals with non-transferable skills that are exposed to high levels of risk, even if they are not in a particularly vulnerable economic situation. According to this line of reasoning risk - and not vulnerability - is the key factor that makes people more responsive to the macro-economic environment.

Hibbs (1982), on the other hand, found that lower-status classes seemed to exhibit greater aversion to unemployment and to be less concerned about inflation than higher status groups. Hibbs' findings, however, are not directly applicable to our argument. His dependent variable is political support and his focus is the overwhelmingly studied 
connection between the economy and the vote. By contrast, we analyze subjective views about the economy and focus on the less studied connection between the objective and subjective economies.

People in the higher income strata are more risk averse because of the higher marginal cost that they can suffer in the event of an external economic shock (i.e. they have more to lose) and because of the greater difficulty of obtaining the same position in the income and the socio-professional status scale in the case of a loss. Risk aversion is thus necessarily associated with higher levels of attentiveness and responsiveness to macroeconomic changes. Since people in the lower strata are already in a difficult situation before a given macro-economic shock, their perception will presumably be less dependent on country specific short-term economic variation. The first step of this argument can be very simply summarized as follows:

$U_{i}=I_{i}-E_{j}$

Where the utility $(U)$ of a given individual $i$ is equal to his income $(I)$ minus a given macroeconomic shock in terms of worsening conditions $(E)$ in a given country $j$. This expectation does not take into account any source of heterogeneity at this point, and assumes that all individuals will be equally affected by worsening macro-economic conditions. If we adapt Iversen and Soskice's (2001) insurance component, however, the effect of the macroeconomic shock should be moderated by the potential risk or marginal cost of a given individual $(R)$. In this case, the bigger the risk $R$ for a given individual, the greater will be the effect of a macro-economic shock on this individual's utility. 
$U_{i}=I_{i}-E_{j} \cdot R_{i}$

As stated above, risk is defined here as a potentially higher marginal cost due to presumably bigger investments on the individuals' side and by higher perceived difficulties of reaching the same position in case of a loss. This implies that $R$ in equation (2) is a relative component, assuming that the marginal loss for people in the higher strata will always be higher than for those in the lower strata.

$\frac{I_{i h}-E_{j}}{I_{i l}-E_{j}}>1$

According to equation 3, the potential loss of income due to a macro-economic shock will be greater for higher strata $h$ than for lower strata $l$. Taken together, if one accepts an interrelation between subjective views about the economy and individual objective economic circumstances, and if one considers the relative risk ratio component expressed in equation (3) as a driver for public attitudes towards the economy, higher income individuals have more reasons to be more dissatisfied with worsening economic conditions. In contrast, individuals in the lower strata have a lower relative risk to assume, since they are already in a difficult situation before the macro-economic shock. 


\section{Data and statistical model}

The dataset employed here is the European Social Survey (ESS) cumulative file. This dataset pools four waves fielded in 2002-2003, 2004-2005, 2006-2007, and 2008-2009. It comprises 29 different countries, allowing us to implement a strong comparative design, which is less frequent in previous studies $^{1}$ (for an exception however see Duch and Stevenson 2010b; although they study the accuracy of citizens' inflation expectations). The overall time span covered by the data is not long (2002-2009) but very relevant for our purposes, as it covers a general period of growth (even though there is cross-country variation in Europe), but also the beginning of the global financial meltdown.

The advantages of using the ESS are three-fold. First, it contains valid and reliable data on individual objective economic conditions, which are the variables of interest here. More specifically, the sociological profile of the ESS allows us to work with comparable data on individual income, occupational sector, social class and other indicators that have been used to construct the socio-professional status index (see below) in a way that other comparative datasets would not allow us to do (such as the Comparative Study of Electoral Systems, the European Value Study, or Eurobarometers). Second, the ESS project makes a special effort in implementing the same sampling designs and translation strategies across countries, which is of special value for comparative research and when using subjective indicators like citizens' degree of satisfaction towards the national economy, which is our dependent variable. Third, the ESS is not an electoral survey, which means that behavioural questions are reduced to a minimum. This reduces the potential for partisan rationalization biases, which are discussed below.

\footnotetext{
${ }^{1}$ More specifically, there are 22 countries in the first wave, 25 countries in the second, 23 countries in the third, and 26 in the fourth.
} 
Our estimation combines three levels of variation: inter-individual, inter-temporal and inter-country variation. In order to simultaneously test individual and country-level variances across a limited number of cross-sectional time points, we follow Lubbers and Scheepers (2010) and implement a three-level hierarchical linear model. Our lower level of analysis is the individual respondent, our second level is the ESS wave in which the survey was fielded (that is to say, a proxy of time), and our third level is the country ${ }^{2}$. Hierarchical linear models are a well-known strategy to estimate correct standard errors when combining different levels of analysis (Goldstein, 1995; Hox, 2010). The formalization of the statistical model implemented below is the following:

$Y_{i j t}=\beta_{0 i j t}+\beta_{1 i j t} X_{i j t}+\beta_{2 j t}\left(Z_{j t}-Z_{j t-1}\right)+\beta_{3 j i t} X_{i j t}\left(Z_{j t}-Z_{j t-1}\right)+\beta_{k i j t}$ controls $+u_{i}+u_{j}+u_{t}+e_{i j t}$

In equation $4, Y$ is the subjective satisfaction towards the national economy of individual $i$, in country $j$, and at time $t . X$ is an individual-level economic characteristic like income or socio-professional status. $Z$ is a macro-level economic indicator like GDP, unemployment or inflation. The third component of equation 4 is a cross-level interaction between personal and macro-economic conditions, which according to the theory outlined above are supposed to moderate individual subjective satisfaction towards the national economy. On the other hand, $u_{i}, u_{j}$, and $u_{t}$ refer to the individual, country and time specific effects not captured by the variables included in the model and represented by the intercept

\footnotetext{
${ }^{2}$ Our results remain unchanged if a cross-classified multilevel design is implemented. Results available upon request.
} 
variances estimated at the three different levels of analysis. Finally, $e$ represents an error component.

The wording of our dependent variable is "On the whole how satisfied are you with the present state of the economy in your country?" The possible answers to this question are given on a scale from 0 to 10 , where 0 means extremely dissatisfied and 10 means extremely satisfied. This question is not the standard retrospective evaluation about recent (last year) economic changes in the country used in economic voting studies, which is not available in the ESS. This means that we cannot challenge previous research on economic voting based on different indicators. As stated above, however, our main aim is rather to understand how citizens form their views on the economy, which is something that has been relatively ignored in the economic voting literature and in public opinion studies more generally. Moreover, we conducted several validity tests with British and Spanish surveys that showed a remarkable degree of association between current and retrospective economic assessments ${ }^{3}$. The advantage of this variable for our purposes is that its wording induces the respondent to think in national rather than personal terms. We believe that this is crucial for a design that aims to assess the conditional effect of personal economic circumstances on assessments about the state of the national economy.

\footnotetext{
${ }^{3}$ Using the British Post-Election Study 2010, we constructed a dummy variable where negative feelings about the current economy are coded as 1 , and all the rest as 0 . We also recoded negative retrospective evaluations as a dummy. When simply cross-tabulating both items, there are $87.40 \%$ of respondents with negative retrospective evaluations who also had negative feelings about the current economy. The Goodman and Kruskal's gamma coefficient of association between categorical variables is 0.41 . On the other hand, we also used the April 2002, 2004, 2006 and 2008 monthly barometers conducted by the Centro de Estudios Sociologicos in Spain (www.cis.es). The gamma coefficients of the association between retrospective and current economic evaluations are significant and with a magnitude of $0.51,0.52,0.46$, and 0.37 respectively.
} 
The main independent variables are country objective macro-economic changes. Three alternative indicators are tested, namely GDP (gross domestic product based on purchasing power parity per capita, in current international dollars $)^{4}$, unemployment rate (\% of total labour force) and inflation of the consumer price index (average consumer prices in terms of percentage change). Instead of using macro-economic values at the time when the different ESS waves were fielded, we use inter-wave macro-economic changes. That is, we subtract the value corresponding to the year when the survey was implemented in each country from the value of the previous wave ${ }^{5}$. By modelling changes instead of actual year values we follow previous research that has argued that fluctuations are more important than actual rates, and that there is a time lag when learning about the economy (Conover, Feldman and Knight, 1986, p. 566; Anderson, 2007; Duch and Stevenson, 2010, p.112; Evans and Pickup, 2010, p1241). The data source for the macro-economic indicators is the World Economic Outlook database, compiled by the International Monetary Fund. We expect that GDP increases should be related to higher levels of subjective satisfaction, whereas unemployment and inflation increases should be related to lower levels of satisfaction.

According to our main hypothesis, macro-economic changes should not be equally perceived across the population. Individual objective economic indicators capturing selfinterested ways of thinking should mediate the connection between the macro objective

\footnotetext{
${ }^{4}$ The results remain unchanged if GDP in percentage terms is used instead. Results also remain unchanged if rates instead of changes are used for all of our macro-economic independent variables. Results can be made available upon request. ${ }^{5}$ In the case that a given country is present in one wave but not in the previous one, we calculate the macro-economic change from two years before. The same applies for all countries included in the first wave of the ESS (2002-2003). On the other hand, when the fieldwork extended over two years in a given country, we use the average of those years. The results remain unchanged if inter-year rather than inter-wave changes are used.
} 
and the micro subjective economy. To test this hypothesis we use two individual-level objective indicators, namely income and socio-professional status. Income is a particularly appropriate indicator to capture individual economic positions. It is a structural and relatively exogenous indicator, but at the same time it is likely to vary over time and to capture variations in self-interest that can moderate the interpretation of the economic reality in the nation. This is why income is a more appropriate indicator than social class, for instance, which is also an exogenous structural indicator but less variable over time, and eventually too broad to capture refined degrees of self-interest. As Palmer and Whitten show (2011), income reduction has taken place in recent years across very different social classes, so the latter will not necessarily be able to capture the same variation as income. The specific indicator available in the ESS is the total net income of the individual taking into account all sources, and it is measured on a 12-point scale.

In order to test the robustness and the validity of our multivariate analyses, we use an alternative individual objective economic indicator: the International Socio-Economic Index of Occupational Status (ISEI) (Ganzeboom, De Graaf and Treiman, 1992). The ISEI index is derived from the International Standard Classification of Occupations (ISCO) and its main advantage is that it maximizes the role of occupation as an intervening variable between education and income. The synthesis between occupation, education and income on this scale perfectly captures the general socio-economic vulnerability of respondents that goes beyond income, and that is both likely to be exogenous and to vary over time. According to the proponents of ISEI, the validity of this index is superior to other internationally accepted occupational prestige scales and class categorizations (Ganzeboom, De Graaf and Treiman, 1992, pp. 2,5,13). More specifically, one of the main 
advantages of ISEI is its continuous nature. This allows us to capture more precisely some variability between occupations that is not adequately measured in traditional and broader categorical schemes.

Our estimations also include a number of control variables. The most relevant variables capture the three competing sources of heterogeneity tested in Duch, Palmer and Anderson (2000): namely political attitudes, information exposure, and personal financial experience. In the multivariate models presented below, we control for the variables capturing these sources of heterogeneity and their interactions with macro-economic indicators. The variable measuring political attitudes is 'voting for the incumbent'. As previously explained, there is a vivid debate about the degree of exogeneity of citizens' economic perceptions. Recently some authors have argued that citizens' economic perceptions are mere rationalizations of their partisan (or ideological) affiliations (Evans and Andersen, 2006; Ladner and Wleizen, 2007; Van der Eijk at al., 2007) ${ }^{6}$. According to this revisionist perspective, people who have voted for the incumbent should have a greater tendency to positively perceive the state of the economy. However even though the rationalization hypothesis is impossible to test without individual longitudinal data, we control for vote recall for any of the parties that were in government at the time when the survey was fielded, on the basis of the European Election Database ${ }^{7}$. A dummy variable results from this coding where 1 equals having voted for any incumbent party, and 0 means not having

\footnotetext{
${ }^{6}$ Other authors, however, suggest that the degree of partisan bias in citizens' assessments about the economy is not strong enough to invalidate the main conclusions that have been drawn from the studies of economic voting (see for instance, Lewis-Beck, Nadeau and Elias, 2008 and the most recent comparative evidence of Nadeau, Lewis-Beck and Belanger, forthcoming) ${ }^{7}$ http://www.nsd.uib.no/european_election_database/ (03/10/2012)
} 
voted for such a party. Again this variable does not seek to test any rationalization or exogeneity hypothesis (as for instance do Nadeau, Lewis-Beck and Belanger, forthcoming) but to exert a strong partisan control for the micro-economic expectation tested below. In case of an endogenous relationship between voting for the incumbent party and satisfaction with the economy, the worse consequence for our research design would be that voting for the incumbent is a particularly strong control and the results validating our hypothesis of interest are conservative.

Information exposure is measured by interest in politics on a 4-point Likert scale, which we recoded to go from "not at all interested" to "very interested". Personal financial experience is measured with an item whose specific wording concerns the "feeling about household's income nowadays" on a 4-point Likert scale going from "living comfortably on present income" to "very difficult on present income". Finally, a number of other control variables have been included in the estimations: being a manual worker (dummy variable, on the basis of the EGP class categorization scheme), unemployed during the last 7 days (dummy variable), female (dummy variable), age, and level of education (measured in terms of years of full-time education completed). All variables, including macro and microindicators, have been recoded to go from 0 to 1 in order to make the magnitudes of the coefficients comparable.

\section{Findings}

Figure 1 plots country-year averages of economic indicators and mean economic satisfaction. The aggregate relationship between GDP increase and satisfaction is positive $(\mathrm{r}=0.55)$. The case of Ireland in 2004 constitutes the dot fitting the line worse, since its 
GDP increase value (the highest in the sample) should have been associated with a higher mean satisfaction. The graph plotting the relationship between inflation increase and average economic satisfaction shows no clear association between both indicators $(r=-$ 0.04), even when Turkey 2004, which is a clear outlier, is removed from the analyses. Finally, the relationship between unemployment increase and satisfaction is negative $(r=$ $-0.27)$. This suggests that, at the macro-level, GDP growth and unemployment have some association with public satisfaction with the economy. This association, however, is not necessarily overwhelming and suggests the possibility that part of the variation of subjective economic perceptions is affected or moderated by individual-level factors.

\section{[FIGURE 1]}

Table 1 goes a step forward and reports mean economic assessments across income groups. This descriptive analysis shows that the differences in economic satisfaction across high and low levels of GDP are bigger for the highest income quantile than for the lowest. Citizens in the highest income category have a mean economic satisfaction of 0.68 (in a 0 1 scale) when GDP increases. Those same citizens have a mean satisfaction of 0.42 when GDP growth is in its lowest category. This implies a $26 \%$ difference. By contrast, low income citizens report a mean satisfaction of 0.39 and 0.32 in the highest and lowest category of GDP increase respectively. This implies a 7\% difference, and therefore a much lower responsiveness to macro-economic changes than higher income strata.

[TABLE 1] 
A similar picture is depicted when looking at unemployment increase. There is a $22 \%$ difference in mean economic satisfaction across low (0.65) and high (0.43) categories of unemployment increase among higher income strata. Among low income citizens, however, there is only a 5\% difference. This higher association between macro-economic changes and economic satisfaction at high levels of income, however, is not confirmed in the case of inflation. The levels of satisfaction remain almost unchanged across levels of inflation increase, both for high (5\% difference) and low income strata ( $1 \%$ difference). Overall, these first descriptive findings suggest that higher income citizens are generally more satisfied than low income strata about the national economy. However, this evidence also reflects a much stronger variation among higher income strata when the macroeconomy varies.

Table 2 tests our expectations in a multivariate analysis. This table presents several hierarchical linear models predicting subjective economic perceptions. The first column of table 1 reports the unconditional effect of the inter-wave change of the three macroeconomic indicators (GDP, inflation and unemployment) considered here without controls. The second column of table 2 reports the effects of the three macro-economic indicators with all the individual-level controls. The third, fourth and fifth columns report the interactions between each macro-economic indicator and income respectively, which constitutes the formal test of our main hypothesis. If a null model with no predictors is run, the intercept variances at all three levels of analysis become significant, thus justifying a hierarchical approach: $0.04(0.0001)$ at the individual-level, $0.002(0.001)$ at the time-level, and $0.01(0.004)$ at the country-level. In terms of total variance to be explained, $4 \%$ of the 
total variance of economic perceptions can be explained through differences over-time, and $19 \%$ through differences between countries. These proportions of variance remain almost the same across model specifications, except for the one reporting the interaction with inflation increase (column 4). In that case, the model fit is slightly worse especially at the wave level, where the variance to be explained is still $17 \%$. The implication of these intercept variances is that most of the variation in economic perceptions is due to individual and not country or time-level factors. This means that objective personal circumstances and ideological heuristics can play a major role in explaining economic satisfaction beyond the real economy.

\section{[TABLE 2]}

According to the first and second columns of table 2, all three macro-economic indicators have a significant connection with individual satisfaction towards the economy in the expected direction. The apparently satisfactory significance level of inflation, however, is misleading. As shown in Figure 1, inflation increase does not have a clear relationship with mean economic satisfaction. It is only when controlling for unemployment increase (correlated with inflation at the -0.2 level) that inflation becomes apparently significant. When specified as a single predictor without controls, inflation increase has no effect $(b=-0.07$; standard error $=0.11 ; p=0.531)$. An increase in GDP is more robustly associated with higher levels of subjective economic satisfaction, and an increase in unemployment is linked to lower levels of satisfaction. Since this is a linear model and all variables have been rescaled from 0 to 1 , the coefficient magnitudes are directly comparable. Among the 
three macro-indicators considered, the impact of variations in GDP appears stronger ( $b=$ $0.29)$, and the impact of variations in unemployment is the second strongest effect $(b=$ $0.22)$.

The purpose of this study is to assess possible sources of heterogeneity in the link between the objective and the subjective economies on the basis of objective personal financial situations. Columns 3, 4 and 5 in Table 2 report the interactions between each macro-economic indicator and individual income with all the controls. The three multiplicative terms of these interactions are significant. This means that the effect of the three macro-economic indicators on economic satisfaction significantly varies across income groups. More specifically, the multiplicative term between GDP and income and between inflation and income are positive and significant. The multiplicative term between unemployment and income is negative and significant. A correct assessment of the impact and significance of these interactions across the whole range of income, however, cannot be completed through the direct interpretation of the multiplicative terms. This would require not only the inclusion of both constitutive terms in the estimation equation, but also the calculus of how the expected marginal effect of one of the independent variables varies as the values of the other independent variable change.

We follow Brambor, Clark and Golder (2006) and plot the marginal effects of the macro-economic indicators on economic satisfaction across different values of individual income. The solid sloping line denotes the marginal effect, and the dashed lines indicate a $95 \%$ confidence interval based on the estimates of columns 3, 4, and 5 of Table 2 respectively. As can be seen in the three graphs of the uppermost plot line in Figure 2, the interactions between GDP increase and income, and between unemployment increase and 
income, are significant and in the expected direction. As predicted by our theory, higher levels of income seem to be more sensitive and responsive to the macro-economy. Citizens in the higher strata are more satisfied than citizens in the lower strata when GDP increases, and less satisfied when unemployment increases.

The interaction between inflation increase and income, however, fails to reach significance. While our conditional argument is valid for GDP and unemployment, the differences in the magnitude of the effect of inflation on economic perceptions across distinct income levels are not significantly different from 0 . Even though the significance of the multiplicative term in column 4 indicates that the effect of inflation varies across income groups (hence the positive slope of the line), the greater uncertainty associated with the main effect of inflation does not allow us to generalize its effect at any level of income. It is important to emphasize that the magnitudes of the interaction estimates are quite substantial. The marginal effect of GDP increase can vary by 0.14 points between the minimum and the maximum value of income (that is, from 0.37 to 0.51 ). On the other hand, the marginal effect of unemployment increase can vary by 0.18 points between the minimum and the maximum value of income (that is, from -0.27 to -0.45 ). If one considers that all variables have been recoded from 0 to 1 and that the maximal marginal effect would be 1 , a $14 \%$ and $18 \%$ increase of the effect of the macro-economy across the whole range of individual income can be considered as substantial magnitudes ${ }^{8}$.

\section{[FIGURE 2]}

\footnotetext{
${ }^{8}$ The interaction between income and unemployment remains significant even when controlling for the interactions between income and GDP, and ISEI and unemployment. This means that the conditional effect of income and unemployment is not merely capturing the effect of growth or professional status. Results available upon request.
} 
Table 3 reports the results of an exact replication of the estimation summarized in Table 2 , but using an alternative indicator of individuals' objective economic circumstances- the ISEI index. As stated above, the objective here is to strengthen the validity of our findings using an alternative model specification and an alternative operationalization of objective individual socio-economic status. The interactions between GDP increase and ISEI, inflation increase and ISEI, and unemployment increase and ISEI are reported in columns 2, 3 and 4 of Table 3 respectively. In terms of proportion of explained variance, all models perform similarly to the ones reported in Table 2 except for the case of the equation in column 3 that includes the interaction of inflation increase with ISEI, which fits the data worse at the inter-temporal level of variation.

In exactly the same way as with income, the multiplicative terms of each macroeconomic indicator and ISEI are significant and positive for GDP and inflation, and significant and negative for unemployment. This means that the effect of the three macroeconomic indicators on subjective views about the economy significantly varies across status groups. The marginal effects of each macro-economic indicator on economic perceptions conditional on ISEI levels are plotted in the bottom row of Figure 2. Following an almost identical pattern as that of income, GDP increases have a positive impact on economic satisfaction, but especially among high values of socio-professional status. Similarly, unemployment increases have a negative impact on economic satisfaction, but especially among people in the high socio-economic strata as well. The conditional effect of inflation on ISEI, however, fails to reach statistical significance because of the uncertainty and small magnitude associated with inflation as a main effect. The magnitudes 
of the effects are very similar to those in the case of income. The marginal effect of GDP increase can vary by 0.13 points between the minimum and the maximum value of ISEI. On the other hand, the marginal effect of unemployment increase can also vary by 0.16 points between the minimum and the maximum value of ISEI. Again, if one bears in mind that according to the scaling of the variables the maximal marginal effect would be 1 , these marginal increases can be considered to be relevant magnitudes ${ }^{9}$.

\section{[TABLE 3]}

It is important to stress that the argument concerning higher relative risk ratios for people in the higher status strata remains when we consider other competing explanations for economic perceptions. Our fully specified estimations include interactions between macroeconomic increases and levels of political interest, feelings about difficulties with household's income, and voting for the incumbent. This means that the mechanism regarding income and status hypothesized here is valid beyond other sources of economic perceptions identified in the literature. As indicated in Tables 2 and 3, GDP increases economic satisfaction especially among highly interested citizens, and unemployment decreases it especially among low interested citizens. When assessing its overall marginal effect, the interaction with inflation is, once again, insignificant. The effect of GDP and

\footnotetext{
${ }^{9}$ We have replicated our models with our dependent variable recoded into 4 categories (to relax the assumption of linearity) and using ordinal generalized linear models with the package "oglm" in Stata 12 (Williams, forthcoming). This has allowed us to model the potentially higher dispersion of economic perceptions among higher income and status strata. In accordance to our hierarchical linear models, the sign and significance of the interactions remain virtually unchanged with GDP and unemployment increase, but become insignificant and with different signs in the case of inflation. Results available upon request.
} 
unemployment is also especially prominent among citizens with low perceptions of difficulties regarding their household income. Egotropic perceptions of economic difficulties moderate the effect of the real economy in a way that is perfectly consistent with our argument. The responsiveness to real macro-economic changes is lower precisely among citizens who already perceive that they have personal financial difficulties. Finally, as expected by supporters of partisan rationalization effects, the main effect of having voted for an incumbent party is always significantly associated with satisfaction with the national economy. The interactions between vote for the incumbent and unemployment increase is significant and in the expected direction, in the sense that incumbent party supporters moderate the negative effect of unemployment. The interactions with GDP and inflation increase, however, are not consistent across model specifications. While they are insignificant when including the ISEI index in the models (Table 3), they are small and with reversed signs when including income ${ }^{10}$.

The magnitude of the multiplicative term of our interaction between GDP and income in Table 2 is higher than the interactions with egotropic feelings and vote for the incumbent, and comparable to the interaction with political interest. As for inflation, the magnitude of the interaction with income is slightly below the interaction with vote recall, and above the other two. As for unemployment, our interaction with income is the strongest. Exactly the same ranking is found when looking at the interactions between the macro-economy and the ISEI index in Table 3. As for the remaining control variables, being a manual worker, unemployed, female, older or less educated, all result in a greater tendency to be less satisfied with the state of the economy in their respective countries.

\footnotetext{
${ }^{10}$ Figures reporting marginal effects for each of the variables included in all interactions terms are available upon request.
} 


\section{Conclusions}

The different factors shaping the link between objective macro-economic results and citizens' economic perceptions have not been systematically studied from a cross-country perspective. In this article, we hypothesize that objective personal economic conditions moderate the extent to which citizens rely on objective economic conditions to form their subjective opinions about the state of the economy. More specifically, we argue, by relying on axioms derived from an asset theory of social policy preferences (Iversen and Soskice, 2001), that citizens with higher income and higher socioeconomic status are more sensitive to objective macro-economic changes.

The findings shown here confirm this hypothesis. The importance of objective personal economic circumstances lies in their conditioning influence on the effect of macro-economic changes (especially in terms of GDP and unemployment changes) on the degree of citizens' satisfaction with the state of the economy. In short, citizens in higher income and status strata are comparatively more satisfied than citizens in lower strata when the economy improves, and more dissatisfied when the economy worsens. Furthermore, since the lower strata were already in a difficult situation before a given macro-economic shock, their level of economic satisfaction appears to be less dependent on the objective economy.

In addition to our contribution to the understanding of how economic evaluations are formed, these results may have relevant implications for electoral accountability. According to our findings, low status citizens are on average less satisfied with the national economy than high status citizens. However, precisely because of a more difficult personal economic experience, low income citizens respond much less to macro-economic changes 
in their subjective national economic perceptions compared to higher income earners. If low status citizens were not capable of judging approximately how their governments are performing in the economic sphere, it would be of little use if their judgments on this matter had any influence on their voting decisions when it comes to fostering accountability for government actions. This is why we believe that it is crucial to devote greater attention to this topic in the future. 


\section{References}

Anderson, C. J. (2007). The end of Economic Voting? Contingency Dilemmas and the Limits of Democratic Accountability. Annual Review of Political Science, 10, 271-296.

Brambor, T.; Clark, W. and Golder, M. (2006) Understanding Interaction Models: Improving Empirical Analyses, Political Analysis,14, 63-82.

Conover, P. J., Feldman, S. and Knight, K. (1986). Judging Inflation and Unemployment: The Origins of Retrospective Evaluations. Journal of Politics, 48, 565-88.

Duch, R. M., Palmer, H. D. and Anderson, C. J. (2000). Heterogeneity in Perceptions of National Economic Conditions. American Journal of Political Science,44, 635-652.

Duch, R. and Stevenson, R. (2008). The Economic Vote: How Political and Economic Institutions Condition Election Results. Cambridge: Cambridge University Press.

Duch, R. M. and Stevenson, R. (2010a). The Global Economy, Competency, and the Economic Vote. The Journal of Politics, 72, 105-123.

Duch, R. M. and Stevenson, R. (2010b). Context and Economic Expectations: When Do Voters Get it Right? British Journal of Political Science, 41, 1-31.

Evans, G., and Andersen, R. (2006). The Political Conditioning of Economic Perceptions. Journal of Politics, 68, 194-207.

Evans, G. and Pickup, M. (2010). Reversing the Causal Arrow: The Political Conditioning of Economic Perceptions in the 2000-2004 US Presidential Election Cycle. The Journal of Politics, 72, 1236-1251

Ganzeboom, H., B.G., De Graaf, P. M. and Treiman, D. J. (1992). A Standard International Socio-economic Index of Occupational Status. Social Science Research, 21, 1-56.

Goldstein, H. (1995). Multilevel Statistical Models. 2nd ed. London: Arnold Hox, J. J. (2010). Multilevel Analysis: Techniques and Applications. London: Routledge. 
Hibbs, D.A. (1982). Economic Outcomes and Political Support for British Governments among Occupational Classes: A Dynamic Analysis. American Political Science Review, $76,259-279$.

Iversen, T. and Soskice, D. (2001). An Asset Theory of Social Policy Preferences. The American Political Science Review, 95, 875-893.

Ladner, M. and Wlezien, C. (2007). Partisan Preferences, Electoral Prospects, and Economic Expectations. Comparative Political Studies, 40, 571-596.

Lewis-Beck, M. S. and Paldam, M. (2000). Economic Voting: An Introduction. Electoral Studies, 19, 113-121.

Lewis-Beck, M. S. and Stegmaier, M. (2000). Economic Determinants of Electoral Outcomes. Annual Review of Political Science, 3, 183-219.

Lewis-Beck, M. S. and Stegmaier, M. (2009). Economic Models of the Vote. In The Oxford Handbook of Political Behavior, ed. Russell Dalton and Hans-Dieter Klingemann. Oxford: Oxford University Press, 518-537.

Lewis-Beck, M.S., Nadeau, R., and Elias, A. (2008). Economics, Party, and the Vote: Causality Issues and Panel Data. American Journal of Political Science, 52, 84-95. Lubbers, M. and Scheepers, P. (2010). Divergent Trends of Euroscepticism in Countries and Regions of the European Union. European Journal of Political Research, 49, 787-817. Meltzer, A. H. and Scott, F. R. (1981). A Rational Theory of the Size of the Government. Journal of Political Economy, 89, 914-927.

Nadeau, R. Lewis-Beck, M. and Bélanger, E. Forthcoming. Economics and Elections Revisited. Comparative Political Studies. 
Palmer, H. D. and Whitten, G.D. (2011) Through Thick and Thin? The Dynamics of Government Support Across Income Groups During Economic Crises. Electoral Studies. $30-3$ (2011), 427-437.

Popkin, S. L. (1991). The Reasoning Voter. Chicago: The University of Chicago Press.

Singer, M. M. (2011). Who Says “It's the Economy”? Cross-National and Cross-Individual Variation in the Salience of Economic Performance. Comparative Political Studies, 44, 284-312

Singer, M. M. (forthcoming). What goes around comes around: Perceived vulnerable employment and economic voting in developing countries. Eurpean Journal of Political Research.

Sniderman, P. M., Brody, R. A. and Tetlock, P. E. (1991). Reasoning and Choice. Explorations in Political Psychology. New York: Cambridge University Press.

Van der Eijk, C., Franklin, M. Demant, F. and van der Drug, W. (2007). The Endogenous Economy: 'Real' Economic Conditions, Subjective Economic Evaluations and Government Support. Acta Politica, 42: 1-22.

Williams, R. (forthcoming) "Estimating heterogenous choice models with oglm", forthcoming in The Stata Journal. 
Figure 1
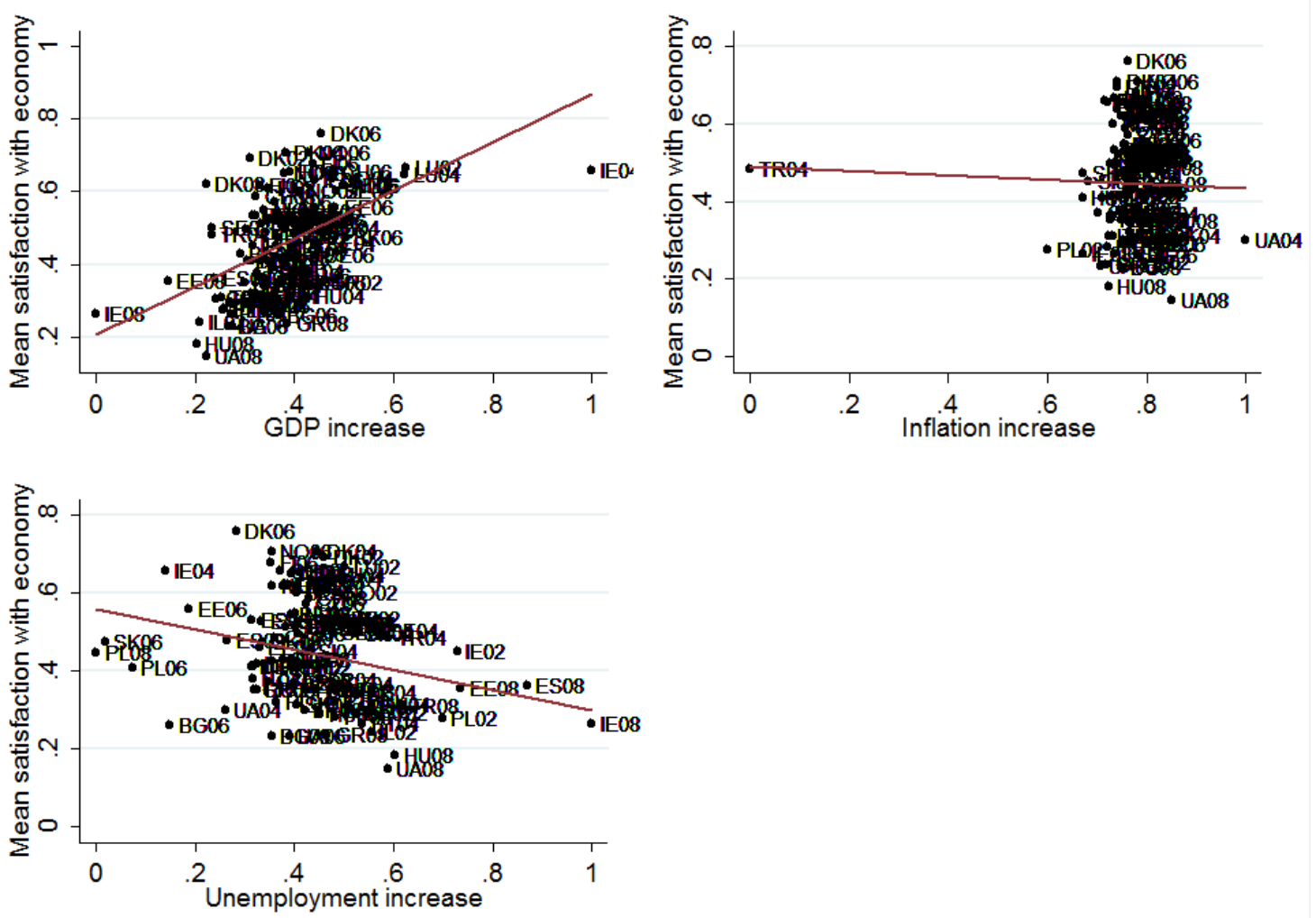
Figure 2
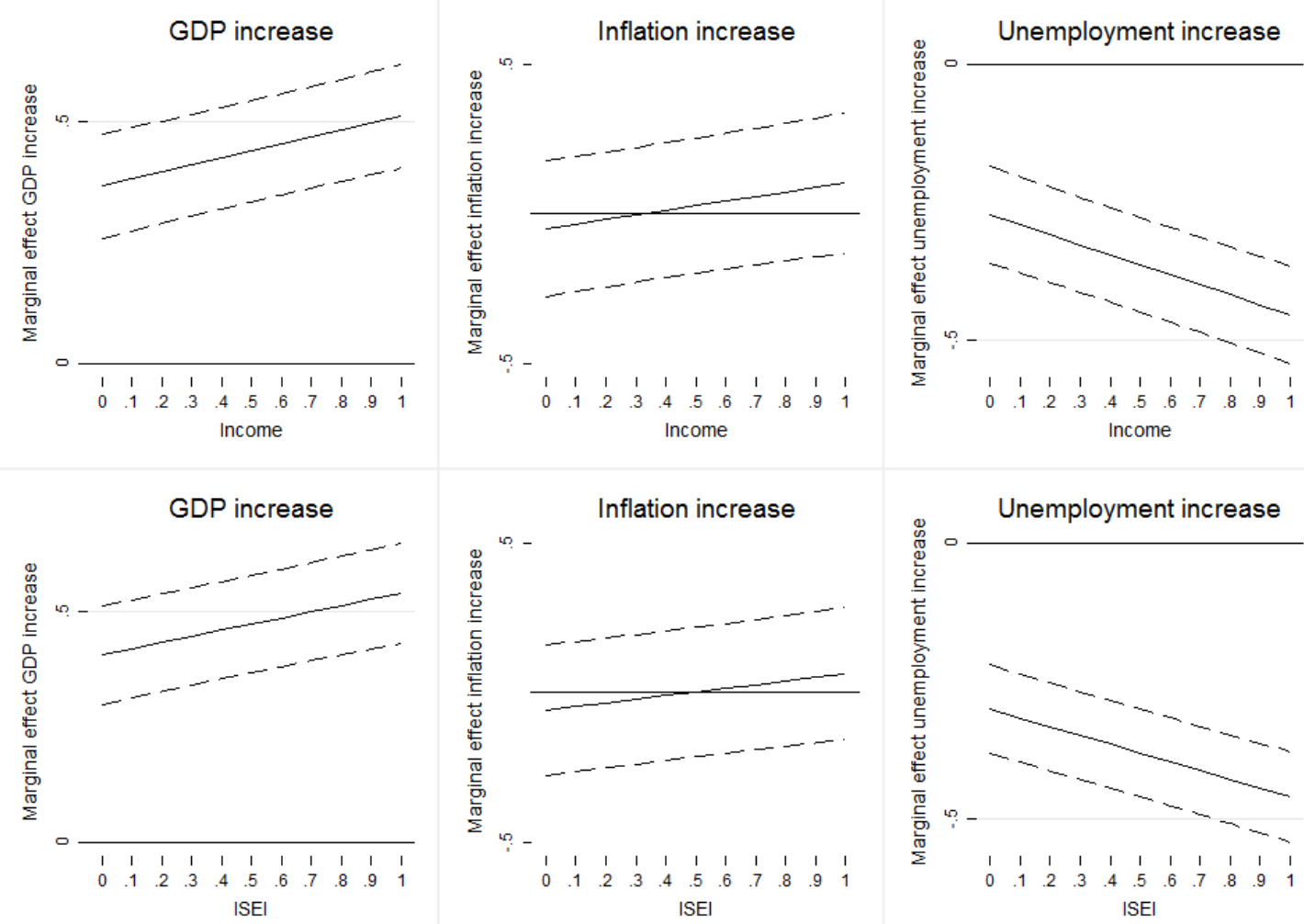

Table 1- Mean economic assessments by income groups

\begin{tabular}{|l|l|l|l|l|l|l|}
\hline & \multicolumn{2}{|c|}{ GDP increase } & \multicolumn{2}{c|}{ Inflation increase } & \multicolumn{2}{c|}{$\begin{array}{l}\text { Unemployment } \\
\text { increase }\end{array}$} \\
\hline & $\begin{array}{l}\text { Highest } \\
\text { quartile }\end{array}$ & $\begin{array}{l}\text { Lowest } \\
\text { quartile }\end{array}$ & $\begin{array}{l}\text { Highest } \\
\text { quartile }\end{array}$ & $\begin{array}{l}\text { Lowest } \\
\text { quartile }\end{array}$ & $\begin{array}{l}\text { Highest } \\
\text { quartile }\end{array}$ & $\begin{array}{l}\text { Lowest } \\
\text { quartile }\end{array}$ \\
\hline $\begin{array}{l}\text { Highest income } \\
\text { sextile (N=26,945) }\end{array}$ & 0.68 & 0.42 & 0.59 & 0.54 & 0.43 & 0.65 \\
\hline $\begin{array}{l}\text { Lowest income sextile } \\
\text { (N=11,836) }\end{array}$ & 0.39 & 0.32 & 0.33 & 0.34 & 0.31 & 0.36 \\
\hline
\end{tabular}

Source: ESS cumulative file

Entries are mean values of satisfaction with the state of the national economy (recoded from 0 to 1 ) 
Table 2- Hierarchical Linear Models: interactions between macro-economy and income

\begin{tabular}{|c|c|c|c|c|c|}
\hline & $\begin{array}{l}\text { Without } \\
\text { controls }\end{array}$ & $\begin{array}{l}\text { With } \\
\text { individual- } \\
\text { level controls }\end{array}$ & $\begin{array}{l}\text { Interaction } \\
\text { with GDP }\end{array}$ & $\begin{array}{l}\text { Interaction } \\
\text { with inflation }\end{array}$ & $\begin{array}{l}\text { Interaction } \\
\text { with } \\
\text { unemployment }\end{array}$ \\
\hline GDP increase & $0.29 * *(0.06)$ & $0.3 * *(0.06)$ & $0.37 * *(0.06)$ & & \\
\hline inflation increase & $-0.16^{*}(0.07)$ & $-0.14 *(0.07)$ & & $-0.05(0.12)$ & \\
\hline $\begin{array}{l}\text { unemployment } \\
\text { increase }\end{array}$ & $-0.22 * *(0.05)$ & $-0.2 * *(0.05)$ & & & $-0.27 * *(0.04)$ \\
\hline income & & & $-0.06 * *(0.01)$ & $-0.12 * *(0.03)$ & $0.07 * *(0.01)$ \\
\hline $\begin{array}{l}\text { macro- } \\
\text { indicator*income }\end{array}$ & & & $0.14 * *(0.03)$ & $0.15 * *(0.04)$ & $-0.18 * *(0.02)$ \\
\hline manual worker & & $-0.02 * *(0.001)$ & $-0.02 * *(0.001)$ & $-0.02 * *(0.001)$ & $-0.02 * *(0.001)$ \\
\hline unemployed & & $-0.03 * *(0.003)$ & $-0.03 * *(0.003)$ & $-0.03 * *(0.003)$ & $-0.03 * *(0.003)$ \\
\hline $\begin{array}{l}\text { perceived } \\
\text { personal } \\
\text { economic } \\
\text { difficulties }\end{array}$ & & $-0.17 * *(0.002)$ & $-0.14 * *(0.01)$ & $-0.1 * *(0.02)$ & $-0.2 * *(0.01)$ \\
\hline female & & $-0.02 * *(0.001)$ & $-0.03 * *(0.001)$ & $-0.03 * *(0.001)$ & $-0.02 * *(0.001)$ \\
\hline age & & $-0.04 * *(0.003)$ & $-0.03 * *(0.004)$ & $-0.03 * *(0.004)$ & $-0.03 * *(0.004)$ \\
\hline education & & $-0.01(0.01)$ & $0.02 *(0.01)$ & $0.02 * *(0.01)$ & $0.02 *(0.01)$ \\
\hline political interest & & $0.01 * *(0.002)$ & $-0.05 * *(0.01)$ & $-0.06^{* *}(0.01)$ & $0.06^{* *}(0.01)$ \\
\hline $\begin{array}{l}\text { vote for } \\
\text { incumbent }\end{array}$ & & $0.04 * *(0.001)$ & $0.05 * *(0.004)$ & $0.18 * *(0.01)$ & $0.02 * *(0.004)$ \\
\hline $\begin{array}{l}\text { macro- } \\
\text { indicator*interest }\end{array}$ & & & $0.16^{* *}(0.02)$ & $0.1 * *(0.02)$ & $-0.11 * *(0.01)$ \\
\hline $\begin{array}{l}\text { macro-indicator* } \\
\text { perceived } \\
\text { personal } \\
\text { economic } \\
\text { difficulties }\end{array}$ & & & $-0.08 * *(0.02)$ & $-0.09 * *(0.02)$ & $0.08 * *(0.02)$ \\
\hline $\begin{array}{l}\text { macro- } \\
\text { indicator*vote } \\
\text { for incumbent }\end{array}$ & & & $-0.02 *(0.01)$ & $-0.19 * *(0.01)$ & $0.04 * *(0.01)$ \\
\hline intercept & $0.55 * *(0.07)$ & $0.6^{* *}(0.07)$ & $0.38 * *(0.03)$ & $0.55 * *(0.09)$ & $0.63 * *(0.03)$ \\
\hline $\begin{array}{l}\text { intercept } \\
\text { variance level-1 }\end{array}$ & $0.04 * *(0.0001)$ & $0.04 * *(0.0001)$ & $0.04 * *(0.0002)$ & $0.04 * *(0.0002)$ & $0.04 * *(0.0001)$ \\
\hline $\begin{array}{l}\text { intercept } \\
\text { variance level-2 }\end{array}$ & $\begin{array}{l}0.002 * * \\
(0.0003)\end{array}$ & $\begin{array}{l}0.002 * * \\
(0.0003)\end{array}$ & $\begin{array}{l}0.002 * * \\
(0.0004)\end{array}$ & $0.01 * *(0.001)$ & $\begin{array}{l}0.002 * * \\
(0.0004)\end{array}$ \\
\hline $\begin{array}{l}\text { intercept } \\
\text { variance level-3 }\end{array}$ & $0.01 * *(0.004)$ & $0.01 * *(0.002)$ & $0.01 * *(0.002)$ & $0.01 * *(0.003)$ & $0.01 * *(0.003)$ \\
\hline N level-1 & 179,513 & 171,378 & 123,223 & 123,223 & 123,223 \\
\hline N level-2 & 96 & 94 & 84 & 84 & 84 \\
\hline N level-3 & 29 & 29 & 29 & 29 & 29 \\
\hline $\begin{array}{l}\text { intraclass } \\
\text { correlation } \\
\text { individuals }\end{array}$ & 0.77 & 0.77 & 0.77 & 0.67 & 0.77 \\
\hline $\begin{array}{l}\text { intraclass } \\
\text { correlation years }\end{array}$ & 0.04 & 0.04 & 0.04 & 0.17 & 0.04 \\
\hline $\begin{array}{l}\text { intraclass } \\
\text { correlation } \\
\text { countries }\end{array}$ & 0.19 & 0.19 & 0.19 & 0.17 & 0.19 \\
\hline AIC & -50403.69 & -59886.49 & -43691.29 & -43740.57 & -43731.5 \\
\hline BIC & -50333.01 & -59735.72 & -43516.3 & -43565.58 & -43556.51 \\
\hline
\end{tabular}

Source: ESS cumulative file

Standard errors between brackets

Dependent variable: satisfaction towards the state of the national economy (from less to more)

$* * \mathrm{p} \leq 0.01 * \mathrm{p} \leq 0.05$ 
Table 3- Hierarchical Linear Models: interactions between macro-economy and ISEI

\begin{tabular}{|c|c|c|c|c|}
\hline & $\begin{array}{l}\text { With } \\
\text { controls }\end{array}$ & $\begin{array}{l}\text { Interaction with } \\
\text { GDP }\end{array}$ & $\begin{array}{l}\text { Interaction } \\
\text { with inflation }\end{array}$ & $\begin{array}{l}\text { Interaction with } \\
\text { unemployment }\end{array}$ \\
\hline GDP increase & $0.3 * *(0.06)$ & $0.41 * *(0.05)$ & & \\
\hline inflation increase & $\begin{array}{l}-0.14^{*} \\
(0.07)\end{array}$ & & $-0.06(0.11)$ & \\
\hline $\begin{array}{l}\text { unemployment } \\
\text { increase }\end{array}$ & $\begin{array}{l}-0.2 * * \\
(0.05)\end{array}$ & & & $-0.3 * *(0.04)$ \\
\hline ISEI & & $-0.04 * *(0.01)$ & $-0.09 * *(.03)$ & $0.07 * *(0.01)$ \\
\hline $\begin{array}{l}\text { macro- } \\
\text { indicator*ISEI }\end{array}$ & & $0.13 * *(0.02)$ & $0.12 * *(0.04)$ & $-0.16^{* *}(0.02)$ \\
\hline manual worker & $\begin{array}{l}-0.02 * * \\
(0.001)\end{array}$ & $-0.01 * *(0.001)$ & $-0.01 * *(0.001)$ & $-0.01 * *(0.001)$ \\
\hline unemployed & $\begin{array}{l}-0.03 * * \\
(0.003) \\
\end{array}$ & $-0.03 * *(0.003)$ & $-0.03 * *(0.003)$ & $-0.03 * *(0.003)$ \\
\hline $\begin{array}{l}\text { personal } \\
\text { economic } \\
\text { difficulties }\end{array}$ & $\begin{array}{l}-0.17 * * \\
(0.002)\end{array}$ & $-0.13 * *(0.01)$ & $-0.13 * *(0.02)$ & $-0.22 * *(0.01)$ \\
\hline female & $\begin{array}{l}-0.02 * * \\
(0.001) \\
\end{array}$ & $-0.02 * *(0.001)$ & $-0.02 * *(0.001)$ & $-0.02 * *(0.001)$ \\
\hline age & $\begin{array}{l}-0.04 * * \\
(0.003)\end{array}$ & $-0.02 * *(0.004)$ & $-0.01 * *(0.004)$ & $-0.02 * *(0.004)$ \\
\hline education & $-0.01(0.01)$ & $0.04 * *(0.01)$ & $0.04 * *(0.01)$ & $0.04 * *(0.01)$ \\
\hline political interest & $\begin{array}{l}0.01 * * \\
(0.002)\end{array}$ & $-0.03 * *(0.01)$ & $-0.01(0.02)$ & $0.05 * *(0.01)$ \\
\hline $\begin{array}{l}\text { vote for } \\
\text { incumbent }\end{array}$ & $\begin{array}{l}0.04 * * \\
(0.001) \\
\end{array}$ & $0.04 * *(0.004)$ & $0.14 * *(0.01)$ & $0.03 * *(0.004)$ \\
\hline $\begin{array}{l}\text { macro- } \\
\text { indicator*interest }\end{array}$ & & $0.13 * *(0.02)$ & $0.04(0.02)$ & $-0.08 * *(0.01)$ \\
\hline $\begin{array}{l}\text { macro-indicator* } \\
\text { perceived } \\
\text { personal } \\
\text { economic } \\
\text { difficulties }\end{array}$ & & $-0.11 * *(0.02)$ & $-0.06 *(0.03)$ & $0.11 * *(0.01)$ \\
\hline $\begin{array}{l}\text { macro- } \\
\text { indicator*vote } \\
\text { for incumbent }\end{array}$ & & $-.005(0.01)$ & $-0.14 * *(0.02)$ & $0.02 * *(0.01)$ \\
\hline intercept & $0.6^{* *}(0.07)$ & $0.35(0.03)$ & $0.54 * *(0.09)$ & $0.62 * *(0.03)$ \\
\hline $\begin{array}{l}\text { intercept } \\
\text { variance level-1 }\end{array}$ & $\begin{array}{l}0.04 * * \\
(0.0001)\end{array}$ & $0.04 * *(0.0001)$ & $0.04 * *(0.0001)$ & $0.04 * *(0.0001)$ \\
\hline $\begin{array}{l}\text { intercept } \\
\text { variance level-2 }\end{array}$ & $\begin{array}{l}0.002 * * \\
(0.0003) \\
\end{array}$ & $0.003 * *(0.0005)$ & $0.01 * *(0.001)$ & $0.002 * *(0.0004)$ \\
\hline $\begin{array}{l}\text { intercept } \\
\text { variance level-3 }\end{array}$ & $\begin{array}{l}0.01 * * \\
(0.002) \\
\end{array}$ & $0.01 * *(0.002)$ & $0.01 * *(0.003)$ & $0.01 * *(0.003)$ \\
\hline N level-1 & 171,378 & 150,211 & 150,211 & 150,211 \\
\hline N level-2 & 94 & 94 & 94 & 94 \\
\hline N level-3 & 29 & 29 & 29 & 29 \\
\hline $\begin{array}{l}\text { intraclass } \\
\text { correlation } \\
\text { individuals }\end{array}$ & 0.77 & 0.75 & 0.67 & 0.77 \\
\hline $\begin{array}{l}\text { intraclass } \\
\text { correlation years }\end{array}$ & 0.04 & 0.06 & 0.17 & 0.04 \\
\hline $\begin{array}{l}\text { intraclass } \\
\text { correlation } \\
\text { countries }\end{array}$ & 0.19 & 0.19 & 0.17 & 0.19 \\
\hline AIC & -59886.49 & -55773.52 & -55610.86 & -55798.09 \\
\hline BIC & -59735.72 & -55594.96 & -55432.3 & -55619.54 \\
\hline
\end{tabular}

Source: ESS cumulative file; Standard errors between brackets; $* * \mathrm{p} \leq 0.01 * \mathrm{p} \leq 0.05$

Dependent variable: satisfaction towards the state of the national economy (from less to more) 
